\title{
Maternal smoking status before and during pregnancy and bronchial asthma at 3 years of age: a prospective cohort study from the Japan Environment and Children's Study (JECS)
}

Kunio Miyake ( $\sim$ kmiyake@yamanashi.ac.jp )

University of Yamanashi: Yamanashi Daigaku https://orcid.org/0000-0001-9196-2229

Megumi Kushima

University of Yamanashi: Yamanashi Daigaku

Ryoji Shinohara

University of Yamanashi: Yamanashi Daigaku

Sayaka Horiuchi

University of Yamanashi: Yamanashi Daigaku

\section{Sanae Otawa}

University of Yamanashi: Yamanashi Daigaku

\section{Yuka Akiyama}

University of Yamanashi: Yamanashi Daigaku

\section{Tadao Ooka}

University of Yamanashi: Yamanashi Daigaku

\section{Reiji Kojima}

University of Yamanashi: Yamanashi Daigaku

Hiroshi Yokomichi

University of Yamanashi: Yamanashi Daigaku

\section{Zentaro Yamagata}

University of Yamanashi: Yamanashi Daigaku

\section{Research}

Keywords: Maternal smoking, childhood asthma, birth cohort, DOHaD

Posted Date: October 19th, 2021

DOl: https://doi.org/10.21203/rs.3.rs-966835/v1

License: (c) (i) This work is licensed under a Creative Commons Attribution 4.0 International License.

Read Full License 
Page $2 / 20$ 


\section{Abstract \\ Background}

Maternal smoking exposure during pregnancy is an established risk factor for childhood asthma, but the association between maternal pre-pregnancy smoking status and asthma risk is not well understood.

This study examined the association between maternal smoking status before and during pregnancy and bronchial asthma at 3 years of age.

\section{Methods}

The data of 75,411 mother-child pairs, excluding the missing data of exposure and outcomes from the Japan Environment and Children's Study (JECS) were used. The association between prenatal maternal smoking status and the risk of bronchial asthma at 3 years of age was determined using multivariate logistic regression analysis.

\section{Results}

The percentage of 3-year-old children with doctor-diagnosed bronchial asthma was $7.2 \%$. The distribution of maternal smoking status before childbirth was as follows: Never $=60.0 \%$, Quit before recognizing current pregnancy $=24.1 \%$, Quit after finding out current pregnancy $=12.3 \%$, and Still smoking $=3.6 \%$. Maternal smoking during pregnancy was significantly associated with an increased risk of bronchial asthma at 3 years of age even after adjusting for pre- and postnatal covariates (adjusted odds ratio [aOR] $1.35,95 \%$ confidence interval $[\mathrm{Cl}] 1.16-1.57)$. Furthermore, mothers who quit before recognizing current pregnancy (aOR 1.10, 95\% $\mathrm{Cl} 1.02-1.18$ ) or who quit after finding out about current pregnancy (aOR 1.11, $95 \% \mathrm{Cl} 1.01-1.23)$ were also significantly associated.

\section{Conclusions}

This study suggested that not only maternal smoking during pregnancy but also maternal smoking exposure of pre-pregnancy or early pregnancy may be associated with an increased risk of bronchial asthma in children.

\section{Introduction}

Asthma is one of the most common illnesses in children. The trend of the prevalence of asthma varies with country and region. The global incidence of asthma is increasing in low-income countries but is flat or decreasing in some developed countries [1]. 
The prevalence of asthma in Japanese schoolchildren has also been declining in recent years $(6.5 \%$ in 2002 and $4.7 \%$ in 2012) [2].

According to a national survey conducted in Japan in 2003, the prevalence of asthma in children (up to 15 years old) was $9.0-13.6 \%$. Several risk factors for asthma in children have been reported, including a history of parental asthma, prenatal smoking exposure, preterm birth, birth by caesarean delivery, postnatal respiratory syncytial virus (RSV) infection, indoor exposure to mould or fungi, and outdoor air pollution $[3,4]$. In contrast, breastfeeding and high dietary fruit intake during pregnancy have been reported to have a protective effect on asthma in children [5, 6]. It is well known that maternal smoking exposure during pregnancy increases the risk of asthma in children [7-9]. However, there are few reports on the involvement of maternal smoking exposure during pregnancy and increased risk of asthma in children, adjusted for various postnatal factors such as breastfeeding, RSV infection, and attending nursery school.

Maternal second-hand smoke (SHS) exposure during pregnancy is also associated with an increased risk of asthma in children [10-12]. Regarding postnatal SHS exposure, five European birth cohort studies from the Mechanisms of the Development of Allergy reported that SHS exposure in infants was not statistically significant but was associated with an increased risk of asthma up to 14-16 years of age [13].

There is controversy about the health effects on children from mothers who quit smoking before or early in pregnancy. A large-scale population-based retrospective cohort study using the United States National Vital Statistics System data from 2011-2018 found that mothers quitting smoking during the first or second trimester of pregnancy are associated with an increased risk of preterm birth [14]. In contrast, it has been reported that maternal smoking cessation before and early in pregnancy does not increase the risk of a small-for-gestational-age infant and childhood overweight at 3 years [15]. Regarding asthma in children, a retrospective hospital-based birth cohort study in Finland found that paternal smoking cessation during pregnancy was associated with a reduced risk of asthma in children, while the effect of maternal smoking cessation during pregnancy and the risk of asthma in children were unclear [16].

Limitations of previous studies include recall bias in retrospective studies, differences in the definition of smoking environment, and the inability to adjust for essential confounding factors. Therefore, there is a need for verification using a large-scale prospective birth cohort. The purpose of this study was to clarify the association between the prenatal maternal smoking status and the risk of bronchial asthma at 3 years of age by adjusting for covariates before and after birth using a large cohort Japan Environment and Children's Study (JECS).

\section{Methods}

\section{Study design and population}


This study used data from JECS, a nationwide birth cohort study. JECS is a project aimed at investigating the effects of environmental factors on child health and development. The detailed protocols have been published elsewhere $[17,18]$. Fifteen Regional Centres across Japan participate in JECS, and women in early pregnancy and their partners who lived in the area around the Regional Centre were recruited and followed up by the Centre. Participants were recruited between January 2011 and March 2014. Participating children will be tracked until they reach the age of 13 years. The JECS protocol was reviewed and approved by the Ministry of the Environment's Institutional Review Board on Epidemiological Studies and the Ethics Committees of all participating institutions (Ethical Number: No.100910001). The JECS is conducted in accordance with the Declaration of Helsinki and with written informed consent from all participants.

We used the dataset 'Jecs-ta-20190930-qsn' which was released in October 2019. Of the 100,304 live births, we excluded those with missing data on maternal smoking status before and after pregnancy and bronchial asthma at 3 years of age. Finally, 75,411 mother-child pairs were analysed in the present study (Figure 1).

\section{Exposure and covariates}

Prenatal parental smoking history and exposure to SHS were collected by a self-administered questionnaire during the second or third trimester of pregnancy. A mother was instructed to choose among whether 'Never'; 'Previously did, but quit before recognizing current pregnancy'; 'Previously did, but quit after finding out current pregnancy'; or 'Yes, I still smoke respective to herself and her partner'. For second-hand smoking, a mother answered how often she had a chance to inhale tobacco smoke at any indoor places at mid/late pregnancy by choosing frequency from either almost never or never, once a week, 2-3 times a week, 4-6 times a week, or every day. We have recategorised it into three categories: seldom, 1-3 times a week, and 4-7 times a week.

Regarding the second-hand smoking of children after birth, a mother was asked in the questionnaire at the age of one and a half years. The mothers answered the question of whether the child is exposed to someone's cigarette smoke by choosing the options of rarely, sometimes, and often. We have recategorised into two, with (sometimes and often) or without (rarely) smokers near children.

There are potential confounding factors for the association between prenatal tobacco smoke exposure and asthma [2-4]. We adjusted the analyses for child sex, mother's history of bronchial asthma, maternal age at birth, pre-pregnancy body mass index, maternal educational level ( $\leq 12$ or $>12$ years), older siblings, gestational age at birth (<37 or $\geq 37$ weeks), and mode of delivery (vaginal or caesarean). Additionally, we adjusted for potential confounding factors after birth with the following: attends a childcare facility at 1 year of age, breastfeeding at 1 year of age, and RS virus infection at 1 year of age.

\section{Outcome definitions}


Information of outcomes was collected using a self-administered questionnaire when the children were 3 years of age. The parents answered the question if your child was diagnosed with bronchial asthma by a doctor after age 2 years. The outcomes of this study were defined using this questionnaire (yes or no).

\section{Statistical analyses}

The association between smoking exposure and bronchial asthma at 3 years of age was subjected to logistic regression analysis to estimate the crude odds ratio (COR) and adjusted odds ratio (aOR), adding all the covariates and $95 \%$ confidence interval $(\mathrm{Cl})$. To elucidate the association between prenatal maternal smoking exposure and bronchial asthma at 3 years of age, we extracted a population without second-hand smoking in children after birth $(n=56,212)$. The association between prenatal maternal smoking exposure and bronchial asthma at 3 years of age was examined using a logistic regression analysis adjusted with covariates excluding second-hand smoking of children at the age of one and a half years. To elucidate the involvement of second-hand smoking in children after birth and bronchial asthma at 3 years of age, logistic regression analysis was performed by stratifying prenatal maternal smoking status. All statistical analyses were performed using SPSS version 27. A p-value of 0.05 (twosided) was considered statistically significant.

\section{Results}

The characteristics of the study participants are shown in Table 1. Among the 75,411 mother-child pairs with complete data, 5430 (7.2\%) children had bronchial asthma at 3 years of age. Regarding the maternal smoking status before childbirth, 45,248 (60.0\%) were counted as 'Never', 18,160 (24.1\%) as 'Previously did, but quit before recognizing current pregnancy', 9,301 (12.3\%) as 'Previously did, but quit after finding out current pregnancy', and 2,702 (3.6\%) as 'Yes, I still smoke'. 
Table 1

Characteristics of the study population

Bronchial asthma at the age of 3 years

\begin{tabular}{|c|c|c|c|}
\hline & Total & No & Yes \\
\hline Maternal smoking status before birth & $\begin{array}{l}75,411 \\
(100)\end{array}$ & $69,981(92.8)$ & $5,430(7.2)$ \\
\hline Never & $\begin{array}{l}45,248 \\
(60.0)\end{array}$ & $42,253(56.0)$ & $2,995(4.0)$ \\
\hline $\begin{array}{l}\text { Previously did, but quit before recognizing current } \\
\text { pregnancy }\end{array}$ & $\begin{array}{l}18,160 \\
(24.1)\end{array}$ & $16,795(22.3)$ & $1,365(1.8)$ \\
\hline $\begin{array}{l}\text { Previously did, but quit after finding out current } \\
\text { pregnancy }\end{array}$ & $\begin{array}{l}9,301 \\
(12.3)\end{array}$ & $8,540(11.3)$ & 761 (1.0) \\
\hline Yes, I still smoke & $2,702(3.6)$ & 2,393 (3.2) & $309(0.4)$ \\
\hline Partner's smoking status before birth & $\begin{array}{l}74,468 \\
(98.7)\end{array}$ & $69,120(91.7)$ & $5,348(7.1)$ \\
\hline Never & $\begin{array}{l}21,503 \\
(28.5)\end{array}$ & $20,096(26.6)$ & $1,407(1.9)$ \\
\hline $\begin{array}{l}\text { Previously did, but quit before recognizing current } \\
\text { pregnancy }\end{array}$ & $\begin{array}{l}18,019 \\
(23.9)\end{array}$ & $16,781(22.3)$ & $1,238(1.6)$ \\
\hline $\begin{array}{l}\text { Previously did, but quit after finding out current } \\
\text { pregnancy }\end{array}$ & $2,136(2.8)$ & $1,990(2.6)$ & $146(0.2)$ \\
\hline Yes, I still smoke & $\begin{array}{l}32,810 \\
(43.5)\end{array}$ & $30,253(40.1)$ & $2,557(3.4)$ \\
\hline Missing data & $943(1.3)$ & & \\
\hline Frequency of second-hand smoke during pregnancy & $\begin{array}{l}75,246 \\
(99.8)\end{array}$ & $69,830(92.6)$ & $5,416(7.2)$ \\
\hline Seldom & $\begin{array}{l}48,573 \\
(64.4)\end{array}$ & $45,302(60.1)$ & $3,271(4.3)$ \\
\hline 1-3 times per week & $\begin{array}{l}14,682 \\
(19.5)\end{array}$ & $13,614(18.1)$ & $1,068(1.4)$ \\
\hline 4-7 times per week & $\begin{array}{l}11,991 \\
(15.9)\end{array}$ & $10,914(14.5)$ & $1,077(1.4)$ \\
\hline Missing data & $165(0.2)$ & & \\
\hline Mother's history of bronchial asthma & $\begin{array}{l}75,128 \\
(99.6)\end{array}$ & $69,718(92.5)$ & $5,410(7.2)$ \\
\hline
\end{tabular}

$\mathrm{n}(\%)$ or mean \pm standard deviation. 
Bronchial asthma at the age of 3 years

No

Yes

Missing data

Maternal age at birth (years)

Missing data

Pre-pregnancy BMI

Missing data

Maternal educational level (years)

$\leq 12$

$>12$

Missing data

Gestational weeks at birth (weeks)

$\geq 37$

$<37$

Missing data

Child sex

Male

Female

Mode of delivery

Vaginal

$\mathrm{n}(\%)$ or mean \pm standard deviation.
67,205

(89.1)

7,923

(10.5)

$283(0.4)$

$31.46 \pm$

4.91

$1(0.0)$

$21.15 \pm$

3.12

$41(0.1)$

75,054

(99.5)

25,051

(33.2)

50,003

(66.3)

$357(0.5)$

75,268

(99.8)

71,345

(94.6)

3,923 (5.2)

$143(0.2)$

75,411

(100.0)

38,573

(51.2)

36,838

(48.8)

75,073

(99.6)

60,347

(80.0)
62,928 (83.4) 4,277 (5.7)

$6,790(9.0)$

$1,133(1.5)$

$31.50 \pm 4.91 \quad 30.98 \pm 4.95$

$21.13 \pm 3.18 \quad 21.28 \pm 3.33$

$69,656(92.4) \quad 5,398(7.2)$

$23,198(30.8) \quad 1,853(2.5)$

$46,458(61.6) \quad 3,545(4.7)$

69,852 (92.6) $\quad 5,416(7.2)$

$66,280(87.9) \quad 5,065(6.7)$

$351(0.5)$

$3,572(4.7)$

$69,981(92.8) \quad 5,430(7.2)$

$35,198(46.7) \quad 3,375(4.5)$

$34,783(46.1) \quad 2,055(2.7)$

69,681 (92.4) $\quad 5,392(7.2)$

$56,099(74.4) \quad 4,248(5.6)$ 
Bronchial asthma at the age of 3 years

Caesarean section

Missing data

Attendance to childcare facility at 1 year of age

No

Yes

Missing data

RS virus infection at 1 year of age

No

Yes

Missing data

Breastfeeding at 1 year of age

No

Yes

Missing data

Older siblings

No

Yes

Missing data

Second-hand smoke of children at the age of one and a half years

No
14,726

(19.5)

$338(0.4)$

73,582

(97.6)

55,643

(73.8)

17,939

(23.8)

1,829 (2.4)

73,880

(98.0)

67,134

(89.0)

6,746 (8.9) $5,831(7.7) \quad 915(1.2)$

1,531 (2.0)

73,437

(97.4)

28,401

(38.7)

45,036

(61.3)

1,974 (2.6)

75,128

(99.6)

35,195

(46.7)

39,933

(52.9)

$283(0.4)$

73,024

(96.8)

56,212

(74.5)
$13,582(18.0) \quad 1,144(1.5)$

$68,337(90.6) \quad 5,245(7.0)$

$52,115(69.1) \quad 3,528(4.7)$

$16,222(21.5) \quad 1,717(2.3)$

$68,596(91.0) \quad 5,284(7.0)$

$62,765(83.2) \quad 4,369(5.8)$

$5,831(7.7) \quad 915(1.2)$

$68,188(92.9) \quad 5,249(7.1)$

$26,183(35.7) \quad 2,218(3.0)$

$42,005(57.2) \quad 3,031(4.1)$

$69,718(92.5) \quad 5,410(7.2)$

$32,982(43.7) \quad 2,213(2.9)$

$36,736(48.7) \quad 3,197(4.2)$

$\mathrm{n}(\%)$ or mean \pm standard deviation. 


\begin{tabular}{|c|c|c|c|}
\hline & & \multicolumn{2}{|c|}{$\begin{array}{l}\text { Bronchial asthma at the age of } \\
3 \text { years }\end{array}$} \\
\hline Yes & $\begin{array}{l}16,812 \\
(22.3)\end{array}$ & $15,418(20.4)$ & $1,394(1.8)$ \\
\hline
\end{tabular}

Table 2 shows the results of the association between smoking exposure status and bronchial asthma at 3 years of age by univariate and multivariate logistic regression analyses. Maternal smoking during pregnancy was significantly associated with a higher risk of bronchial asthma at 3 years of age compared to never smoking in univariate (COR 1.82, 95\% Cl 1.61-2.06) and multivariate (aOR 1.35, 95\% $\mathrm{Cl} 1.16-1.57)$ analyses. Furthermore, mothers who quit before recognizing current pregnancy (COR 1.15, $95 \% \mathrm{Cl} 1.07-1.28$; aOR $1.10,95 \% \mathrm{Cl} 1.02-1.18$ ) or who quit after finding out current pregnancy (cOR 1.26, $95 \% \mathrm{Cl} 1.16-1.37$; aOR $1.11,95 \% \mathrm{Cl} 1.01-1.23$ ) were also significantly associated with a higher risk of bronchial asthma at 3 years of age compared to never smoking. Mothers who were frequently exposed to SHS at home, workplace, or any other indoor places during pregnancy were significantly associated with a higher risk of bronchial asthma at 3 years age compared to mothers who were seldom exposed to SHS (cOR 1.37, 95\% Cl 1.13-1.29; aOR 1.13, 95\% Cl 1.03-1.23). Children exposed to SHS after birth had a significantly higher risk of bronchial asthma at 3 years old compared to unexposed children (COR 1.25, 95\% Cl 1.17-1.33; aOR 1.11, 95\% Cl 1.03-1.20). 
Table 2

Association between smoking exposure and risk of bronchial asthma at the age of 3 years COR $(95 \% \mathrm{Cl}) \quad$ aOR $(95 \% \mathrm{Cl})$

\section{Maternal smoking status before birth}

Never

1.00

1.00

Quit before recognizing current pregnancy

$1.15(1.07-$

1.23)

$1.10(1.02-$

1.18)

Quit after finding out current pregnancy

$1.26(1.16-$

$1.12(1.02-$

1.37)

1.23)

Still smoke

$1.82(1.61-$

2.06)

$1.37(1.18-$

1.59)

\section{Partner's smoking status before birth}

Never

1.00

1.00

Quit before recognizing current pregnancy

$1.05(0.97-$

1.14)

$1.02(0.94-$

1.11)

Quit after finding out current pregnancy

$1.05(0.88-$

$1.25)$

$1.01(0.84-$

$1.21(1.13-$

1.29)

1.22)

Still smoke

1.29)

$1.03(0.95-$

1.11)

\section{Frequency of second-hand smoke during pregnancy}

Seldom

1-3 times per week

4-7 times per week
1.00

$1.09(1.01-$

1.17)

$1.37(1.27-$

1.47)
1.00

$0.99(0.92-$

1.07)

$1.13(1.03-$

1.23)

\section{Second-hand smoke of children at the age of one and a half} years

No

1.00

1.00

Yes

$1.25(1.17-$

1.33)

$1.11(1.03-$

1.19)

Adjusted for maternal and partner's smoking status before birth, frequency of second-hand smoke during pregnancy, mother's history of bronchial asthma, maternal age at birth, pre-pregnancy body mass index, maternal educational level, child sex, gestational age at birth, mode of delivery, attendance to childcare facility at 1 year of age, respiratory syncytial virus infection at 1 year of age, breastfeeding at 1 year of age, older siblings.

To clarify the association between prenatal maternal smoking status and bronchial asthma at 3 years of age, we examined children who were not exposed to SHS after birth $(n=56,212)$ (Table 3). Maternal 
smoking during pregnancy was significantly associated with a higher risk of bronchial asthma at 3 years of age compared to never smoking (COR 1.93, 95\% Cl 1.60- 2.32; aOR 1.40, 95\% Cl 1.12-1.75). Mothers who quit smoking before pregnancy were also significantly associated with a higher risk of bronchial asthma at 3 years of age compared to never smoking. Mothers who quit before recognizing current pregnancy (cOR 1.17, 95\% Cl 1.08-1.26; aOR 1.12, 95\% Cl 1.03-1.22) or who quit after finding out current pregnancy (cOR 1.25, 95\% $\mathrm{Cl} 1.12-1.39$; aOR $1.16,95 \% \mathrm{Cl} 1.02-1.30$ ) were also significantly associated with a higher risk of bronchial asthma at 3 years of age compared to never smoking.

Table 3

Association between prenatal maternal smoking status and risk of bronchial asthma at the age of 3 years in participants without postnatal second-hand smoke exposure

\begin{tabular}{|c|c|c|c|}
\hline & $\mathrm{n}(\%)$ & cOR $(95 \% \mathrm{Cl})$ & aOR (95\% Cl) \\
\hline \multicolumn{4}{|l|}{ Maternal smoking status before birth } \\
\hline Never & $36106(82.0)$ & 1.00 & 1.00 \\
\hline Quit before recognizing current pregnancy & $13296(75.6)$ & $1.17(1.08-1.26)$ & $1.12(1.03-1.22)$ \\
\hline Quit after finding out current pregnancy & $5666(63.7)$ & $1.25(1.12-1.39)$ & $1.16(1.02-1.30)$ \\
\hline Still smoke & $1144(45.4)$ & $1.93(1.60-2.32)$ & $1.40(1.12-1.75)$ \\
\hline \multicolumn{4}{|c|}{$\begin{array}{l}n(\%) \text { mean no child is exposed to someone's cigarette smoke in each group at the age of one and a } \\
\text { half years. }\end{array}$} \\
\hline \multicolumn{4}{|c|}{$\begin{array}{l}\text { Adjusted for partner's smoking status before birth, frequency of second-hand smoke during } \\
\text { pregnancy, mother's history of bronchial asthma, maternal age at birth, pre-pregnancy body mass } \\
\text { index, maternal educational level, child sex, gestational age at birth, mode of delivery, attendance to } \\
\text { childcare facility at } 1 \text { year of age, respiratory syncytial virus infection at } 1 \text { year of age, breastfeeding } \\
\text { at } 1 \text { year of age, older siblings. }\end{array}$} \\
\hline
\end{tabular}

Subsequently, to clarify the effects of postnatal SHS exposure, a logistic regression analysis was performed by stratifying the maternal smoking status before childbirth (Table 4). In a group of mothers who had never smoked before childbirth, children exposed to SHS after birth were significantly associated with a higher risk of bronchial asthma at 3 years of age compared to unexposed children (aOR 1.23, 95\% $\mathrm{Cl}$ 1.11-1.37). In contrast, there was no significant difference in the risk of bronchial asthma at 3 years of age among children exposed to SHS after birth and unexposed children in any group of mothers who smoked before childbirth. 
Table 4

Association between postnatal second-hand smoke exposure and risk of bronchial asthma at the age of 3 years

\begin{tabular}{|c|c|c|c|c|}
\hline $\begin{array}{l}\text { Maternal smoking status before } \\
\text { birth }\end{array}$ & $\begin{array}{l}\text { Postnatal SHS } \\
\text { exposure }\end{array}$ & n (\%) & $\begin{array}{l}\mathrm{cOR}(95 \% \\
\mathrm{Cl})\end{array}$ & $\begin{array}{l}\mathrm{aOR}(95 \% \\
\mathrm{Cl})\end{array}$ \\
\hline \multirow[t]{2}{*}{ Never } & No & $\begin{array}{l}36106 \\
(82.0)\end{array}$ & 1.00 & 1.00 \\
\hline & Yes & $\begin{array}{l}7915 \\
(18.0)\end{array}$ & $\begin{array}{l}1.26(1.15- \\
1.38)\end{array}$ & $\begin{array}{l}1.23(1.11- \\
1.37)\end{array}$ \\
\hline \multirow[t]{2}{*}{$\begin{array}{l}\text { Quit before recognizing current } \\
\text { pregnancy }\end{array}$} & No & $\begin{array}{l}13296 \\
(75.6)\end{array}$ & 1.00 & 1.00 \\
\hline & Yes & $\begin{array}{l}4298 \\
(24.4)\end{array}$ & $\begin{array}{l}1.13(0.99- \\
1.29)\end{array}$ & $\begin{array}{l}1.05(0.91- \\
1.21)\end{array}$ \\
\hline \multirow[t]{2}{*}{$\begin{array}{l}\text { Quit after finding out current } \\
\text { pregnancy }\end{array}$} & No & $\begin{array}{l}5666 \\
(63.7)\end{array}$ & 1.00 & 1.00 \\
\hline & Yes & $\begin{array}{l}3222 \\
(36.3)\end{array}$ & $\begin{array}{l}1.11(0.95- \\
1.30)^{(}\end{array}$ & $\begin{array}{l}1.01(0.85- \\
1.20)\end{array}$ \\
\hline \multirow[t]{2}{*}{ Still smoke } & No & $\begin{array}{l}1144 \\
(45.4)\end{array}$ & 1.00 & 1.00 \\
\hline & Yes & $\begin{array}{l}1377 \\
(54.6)\end{array}$ & $\begin{array}{l}0.97(0.76- \\
1.25)\end{array}$ & $\begin{array}{l}1.05(0.79- \\
1.39)\end{array}$ \\
\hline \multicolumn{5}{|c|}{$\begin{array}{l}\text { Adjusted for partner's smoking status before birth, frequency of second-hand smoke during } \\
\text { pregnancy, mother's history of bronchial asthma, maternal age at birth, pre-pregnancy body mass } \\
\text { index, maternal educational level, child sex, gestational age at birth, mode of delivery, attendance to } \\
\text { childcare facility at } 1 \text { year of age, respiratory syncytial virus infection at } 1 \text { year of age, breastfeeding } \\
\text { at } 1 \text { year of age, older sibling. }\end{array}$} \\
\hline
\end{tabular}

\section{Discussion}

In a large birth cohort study, we found strong evidence that maternal smoking during pregnancy was associated with an increased risk of bronchial asthma at 3 years of age even when adjusted for postnatal covariates such as attendance to nursery school, breastfeeding, and RS virus infection. Additionally, we found that mothers who had smoked in early pregnancy and before pregnancy were also significantly associated with an increased risk of bronchial asthma at 3 years of age.

Several cohort studies have previously reported that maternal smoking during pregnancy increases the risk of asthma in children. In a meta-analysis of eight European birth cohorts [8], maternal smoking during pregnancy is associated with asthma at preschool age, with an adjusted odds ratio of 1.65 (95\% $\mathrm{Cl} 1.18-2.31)$. In a large-scale cohort study $(n=60,254)$ in Finland [19], both maternal light $(<10$ cigarettes per day) and heavy (>10 cigarettes per day) smoking during pregnancy had significantly increased risk of asthma by 7 years of age with odds ratios of 1.23 (95\% $\mathrm{Cl} 1.07-1.42)$ and 1.35 (95\% $\mathrm{Cl} 1.13-1.62)$, respectively, compared to never smoking. Our large birth cohort study found that the risk of bronchial 
asthma at 3 years of age increases not only with the number of cigarettes smoked per day, but also with the duration of smoking (Figure S1). The association between pre- and postnatal SHS exposure and the development of asthma in children is controversial $[10,13,20]$. Our results found that mothers who were frequently exposed to SHS at home, workplace, or any other indoor places during pregnancy were associated with an increased risk of bronchial asthma in 3-year-old children. Additionally, postnatal SHS exposure significantly increased the risk of bronchial asthma at 3 years of age even after prenatal smoking exposure and adjusting for other covariates.

We found that prenatal smoking exposure was associated with an increased risk of bronchial asthma at 3 years of age, even without the effects of postnatal smoking exposure. The concept of Developmental Origins of Health and Disease (DOHaD) is considered a molecular mechanism that links prenatal smoking exposure and bronchial asthma. DOHaD evaluates how the early life environment can impact the risk of non-communicable diseases from childhood to adulthood [21]. Epigenetic modifications such as DNA methylation are considered the molecular mechanism of DOHaD [22-24]. Maternal smoking during pregnancy has been shown to alter umbilical cord blood DNA methylation in various genes such as aryl-hydrocarbon receptor repressor $(A H R R)$, cytochrome P450 family 1 subfamily A member 1 (CYP1A1), growth factor-independent 1 transcriptional repressor (GFI1), and myosin IG (MYO1G) $[25,26]$. It has been suggested that this DNA methylation change is maintained throughout the life course [27, 28]. Neophytou et al. showed that it suggests a potential mediation of $A H R R$ methylation in the association between maternal smoking during pregnancy and asthma in Latino children [29]. Gao also showed a synergistic effect of prenatal maternal smoking and $A X L$ receptor tyrosine kinase $(A X L)$ methylation on the risk of childhood bronchitis symptoms [30]. Thus, although methylation of several genes has been reported to be associated with maternal smoking exposure and the risk of childhood asthma, it is necessary to elucidate the molecular mechanisms underlying the development of asthma in the future.

The present study is the first report that mothers who quit before recognizing current pregnancy or quit after finding out about current pregnancy also had a significantly increased risk of bronchial asthma at 3 years of age even without the effects of SHS exposure. It has been suggested that pre-conception exposure to tobacco, chemicals, and stress can cause epigenomic changes in germ cells, adversely affecting the health of the next generation [31]. Pre-pregnancy female mouse exposure to cyclophosphamide, a widely used drug in the treatment of breast cancer, has been shown to alter DNA methylation in F1 and F2 mouse oocytes [32]. Wu et al. recently reported that prenatal paternal smoking exposure increased DNA methylation of immune-related genes, such as LMO2 and IL-10 and correlated with the development of asthma in children [33]. Furthermore, a three-generation cohort study suggests that maternal smoking before conception is associated with an increased risk of childhood asthma [34, 35]. Therefore, it is suggested that epigenetic changes due to the parental smoking history may be transmitted on to the next generation through germ lines even if they are not smoking during pregnancy. It is important for mothers to quit smoking early before pregnancy, as we have shown that the longer the mother quits smoking, the lower the risk of bronchial asthma at 3 years of age. 
This study has several limitations. First, the smoking status of parents was self-reported and may be misclassified. Previous reports using the same dataset reported that $78 \%$ of passive smokers might be misclassified as non-smokers [36]. However, we analysed based on previously reported cut-offs based on urinary cotinine concentration and found no significant association between SHS and increased risk of bronchial asthma at 3 years of age(Table S1). Second, the effects of SHS on children after birth are conducted using a one-and-a-half-year-old questionnaire. Passive smoking exposure of postnatal children was investigated using a questionnaire at the age of one and a half years. It is unknown how long a child was exposed to SHS from birth to age 3 years. Finally, we have adjusted for the essential confounding factors identified in previous studies, but observational studies cannot exclude the possibility of residual confounding.

\section{Conclusions}

Our results strengthened the existing evidence that maternal smoking during pregnancy increases the risk of childhood bronchial asthma in a large birth cohort study, further identifying new features in this association. We have suggested that the effects of maternal smoking even before pregnancy may increase the risk of asthma in children. Therefore, it is important for both parents to quit smoking early to reduce the risk of future health hazards to their children.

\section{Abbreviations}

AHRR

aryl-hydrocarbon receptor repressor

$\mathrm{aOR}$

adjusted odds ratio

AXL

$A X L$ receptor tyrosine kinase

$\mathrm{Cl}$

confidence interval

COR

crude odds ratio

CYP1A1

cytochrome P450 family 1 subfamily A member 1

DOHaD

Developmental Origins of Health and Disease

GFI1

growth factor-independent 1 transcriptional repressor

JECS

Japan Environment and Children's Study

MY01G 
myosin IG

RSV

respiratory syncytial virus

SHS

second-hand smoke.

\section{Declarations}

\section{Ethics approval and consent to participate}

The JECS protocol was reviewed and approved by the Ministry of the Environment's Institutional Review Board on Epidemiological Studies and the Ethics Committees of all participating institutions (Ethical Number: No.100910001). The JECS is conducted in accordance with the Declaration of Helsinki and with written informed consent from all participants.

\section{Consent for publication}

Not applicable.

\section{Availability of data and materials}

Data are unsuitable for public deposition due to ethical restrictions and legal framework of Japan. It is prohibited by the Act on the Protection of Personal Information (Act No. 57 of 30 May 2003, amendment on 9 September 2015) to publicly deposit the data containing personal information. Ethical Guidelines for Medical and Health Research Involving Human Subjects enforced by the Japan Ministry of Education, Culture, Sports, Science and Technology and the Ministry of Health, Labour and Welfare also restricts the open sharing of the epidemiologic data. All inquiries about access to data should be sent to: jecsen@nies.go.jp. The person responsible for handling enquiries sent to this e-mail address is Dr Shoji F.Nakayama, JECS Programme Office, National Institute for Environmental Studies.

\section{Competing interests}

The authors declare that they have no conflict of interest.

\section{Funding}

This study was funded by the Ministry of the Environment, Japan. The findings and conclusions of this article are solely the responsibility of the authors and do not represent the official views of the above government.

\section{Authors' contributions}

KM conceived and designed the study. MK, R. S, SH, SO, ZY, and JECS group collected the data. KMwrote the first draft of the manuscript. MK, RS, SH, SO, YA, TO, RK, HY, ZY revised the manuscript. All authors 
read and approved the final manuscript.

\section{Acknowledgments}

We thank all the participants and Co-operating health care providers for their contribution to the JECS.

Members of the JECS Group as of 2021: Michihiro Kamijima (principal investigator, Nagoya City University, Nagoya, Japan), Shin Yamazaki (National Institute for Environmental Studies, Tsukuba, Japan), Yukihiro Ohya (National Center for Child Health and Development, Tokyo, Japan), Reiko Kishi (Hokkaido University, Sapporo, Japan), Nobuo Yaegashi (Tohoku University, Sendai, Japan), Koichi Hashimoto (Fukushima Medical University, Fukushima, Japan), Chisato Mori (Chiba University, Chiba, Japan), Shuichi Ito (Yokohama City University, Yokohama, Japan), Zentaro Yamagata (University of Yamanashi, Chuo, Japan), Hidekuni Inadera (University of Toyama, Toyama, Japan), Takeo Nakayama (Kyoto University, Kyoto, Japan), Hiroyasu Iso (Osaka University, Suita, Japan), Masayuki Shima (Hyogo College of Medicine, Nishinomiya, Japan), Youichi Kurozawa (Tottori University, Yonago, Japan), Narufumi Suganuma (Kochi University, Nankoku, Japan), Koichi Kusuhara (University of Occupational and Environmental Health, Kitakyushu, Japan), and Takahiko Katoh (Kumamoto University, Kumamoto, Japan).

\section{References}

1. Akinbami LJ, Simon AE, Rossen LM. Changing Trends in Asthma Prevalence Among Children. Pediatrics. 2016;137:1-7.

2. Arakawa H, Adachi Y, Ebisawa M, Fujisawa T. Japanese guidelines for childhood asthma 2020. Allergol Int. 2020;69:314-30.

3. Bao Y, Chen Z, Liu E, Xiang L, Zhao D, Hong J. Risk Factors in Preschool Children for Predicting Asthma During the Preschool Age and the Early School Age: a Systematic Review and Meta-Analysis. Curr Allergy Asthma Rep. 2017;17:85.

4. Stern J, Pier J, Litonjua AA. Asthma epidemiology and risk factors. Semin Immunopathol. 2020;42:5-15.

5. Azad MB, Vehling L, Lu Z, Dai D, Subbarao P, Becker AB, et al. Breastfeeding, maternal asthma and wheezing in the first year of life: a longitudinal birth cohort study. Eur Respir J. 2017;49:1602019.

6. Nurmatov U, Devereux G, Sheikh A. Nutrients and foods for the primary prevention of asthma and allergy: systematic review and meta-analysis. J Allergy Clin Immunol. 2011;127:724-33.

7. Gilliland FD, Li YF, Peters JM. Effects of maternal smoking during pregnancy and environmental tobacco smoke on asthma and wheezing in children. Am J Respir Crit Care Med. 2001;163:429-36.

8. Neuman A, Hohmann C, Orsini N, Pershagen G, Eller E, Kjaer HF, et al. Maternal smoking in pregnancy and asthma in preschool children: a pooled analysis of eight birth cohorts. Am J Respir Crit Care Med. 2012;186:1037-43. 
9. Thacher JD, Gruzieva O, Pershagen G, Neuman A, Wickman M, Kull I, et al. Pre- and postnatal exposure to parental smoking and allergic disease through adolescence. Pediatrics. 2014;134:42834.

10. Simons E, To T, Moineddin R, Stieb D, Dell SD. Maternal second-hand smoke exposure in pregnancy is associated with childhood asthma development. J Allergy Clin Immunol Pract. 2014;2:201-7.

11. Harju M, Keski-Nisula L, Georgiadis L, Heinonen S. Parental smoking and cessation during pregnancy and the risk of childhood asthma. BMC Public Health. 2016;16:428.

12. Tanaka K, Arakawa M, Miyake Y. Perinatal smoking exposure and risk of asthma in the first three years of life: A prospective prebirth cohort study. Allergol Immunopathol. 2020;48:530-6.

13. Thacher JD, Gehring U, Gruzieva O, Standl M, Pershagen G, Bauer CP, et al. Maternal Smoking during Pregnancy and Early Childhood and Development of Asthma and Rhinoconjunctivitis - a MeDALL Project. Environ Health Perspect. 2018;126:047005.

14. Liu B, Xu G, Sun Y, Qiu X, Ryckman KK, Yu Y, et al. Maternal cigarette smoking before and during pregnancy and the risk of preterm birth: A dose-response analysis of 25 million mother-infant pairs. PLoS Med. 2020;17:e1003158.

15. Suzuki K, Sato M, Zheng W, Shinohara R, Yokomichi H, Yamagata Z. Effect of maternal smoking cessation before and during early pregnancy on fetal and childhood growth. J Epidemiol. 2014;24:60-6.

16. Harju M, Keski-Nisula L, Georgiadis L, Heinonen S. Parental smoking and cessation during pregnancy and the risk of childhood asthma. BMC Public Health. 2016;16:428.

17. Kawamoto T, Nitta H, Murata K, Toda E, Tsukamoto N, Hasegawa M, et al. Rationale and study design of the Japan environment and children's study (JECS). BMC Public Health. 2014;14:25.

18. Michikawa T, Nitta H, Nakayama SF, Yamazaki S, Isobe T, Tamura K, et al. Baseline Profile of Participants in the Japan Environment and Children's Study (JECS). J Epidemiol. 2018;28:99-104.

19. Jaakkola JJ, Gissler M. Maternal smoking in pregnancy, fetal development, and childhood asthma. Am J Public Health. 2004;94:136-40.

20. Martín-Pujol A, Fernández E, Schiaffino A, Moncada A, Ariza C, Blanch C, et al. Tobacco smoking, exposure to second-hand smoke, and asthma and wheezing in schoolchildren: a cross-sectional study. Acta Paediatr. 2013;102:e305-9.

21. Barker DJ. The origins of the developmental origins theory. J Intern Med. 2007;261:412-7.

22. Bianco-Miotto T, Craig JM, Gasser YP, van Dijk SJ, Ozanne SE. Epigenetics and DOHaD: from basics to birth and beyond. J Dev Orig Health Dis. 2017 Oct;8(5):513-9.

23. Safi-Stibler S, Gabory A. Epigenetics and the Developmental Origins of Health and Disease: Parental environment signalling to the epigenome, critical time windows and sculpting the adult phenotype. Semin Cell Dev Biol. 2020;97:172-80.

24. Sheikhpour M, Maleki M, Ebrahimi Vargoorani M, Amiri V. A review of epigenetic changes in asthma: methylation and acetylation. Clin Epigenetics. 2021;13:65. 
25. Joubert BR, Håberg SE, Nilsen RM, Wang X, Vollset SE, Murphy SK, et al. 450K epigenome-wide scan identifies differential DNA methylation in newborns related to maternal smoking during pregnancy. Environ Health Perspect. 2012;120:1425-31.

26. Miyake K, Kawaguchi A, Miura R, Kobayashi S, Tran NQV, Kobayashi S, et al. Association between DNA methylation in cord blood and maternal smoking: the Hokkaido Study on Environment and Children's Health. Sci Rep. 2018;8:5654.

27. Richmond RC, Simpkin AJ, Woodward G, Gaunt TR, Lyttleton O, McArdle WL, et al. Prenatal exposure to maternal smoking and offspring DNA methylation across the lifecourse: findings from the Avon Longitudinal Study of Parents and Children (ALSPAC). Hum Mol Genet. 2015;24:2201-17.

28. Lee KW, Richmond R, Hu P, French L, Shin J, Bourdon C, et al. Prenatal exposure to maternal cigarette smoking and DNA methylation: epigenome-wide association in a discovery sample of adolescents and replication in an independent cohort at birth through 17 years of age. Environ Health Perspect. 2015;123:193-9.

29. Neophytou AM, Oh SS, Hu D, Huntsman S, Eng C, Rodríguez-Santana JR, et al. In utero tobacco smoke exposure, DNA methylation, and asthma in Latino children. Environ Epidemiol. 2019;3:e048.

30. Gao L, Liu X, Millstein J, Siegmund KD, Dubeau L, Maguire RL, et al. Self-reported prenatal tobacco smoke exposure, $\mathrm{AXL}$ gene-body methylation, and childhood asthma phenotypes. Clin Epigenetics. 2018;10:98.

31. Barouki R, Melén E, Herceg Z, Beckers J, Chen J, Karagas M, et al. Epigenetics as a mechanism linking developmental exposures to long-term toxicity. Environ Int. 2018;114:77-86.

32. Di Emidio G, D'Aurora M, Placidi M, Franchi S, Rossi G, Stuppia L, et al. Pre-conceptional maternal exposure to cyclophosphamide results in modifications of DNA methylation in F1 and F2 mouse oocytes: evidence for transgenerational effects. Epigenetics. 2019;14:1057-64.

33. Wu CC, Hsu TY, Chang JC, Ou CY, Kuo HC, Liu CA, et al. Paternal Tobacco Smoke Correlated to Offspring Asthma and Prenatal Epigenetic Programming. Front Genet. 2019;10:471.

34. Bråbäck L, Lodge CJ, Lowe AJ, Dharmage SC, Olsson D, Forsberg B. Childhood asthma and smoking exposures before conception-A three-generational cohort study. Pediatr Allergy Immunol. 2018;29:361-8.

35. Accordini S, Calciano L, Johannessen A, Portas L, Benediktsdóttir B, Bertelsen RJ, et al. A threegeneration study on the association of tobacco smoking with asthma. Int $\mathrm{J}$ Epidemiol. 2018;47:1106-17.

36. Nishihama $Y$, Nakayama SF, Tabuchi T, Isobe T, Jung CR, Iwai-Shimada M, et al. Determination of Urinary Cotinine Cut-Off Concentrations for Pregnant Women in the Japan Environment and Children's Study (JECS). Int J Environ Res Public Health. 2020;17:5537.

\section{Figures}




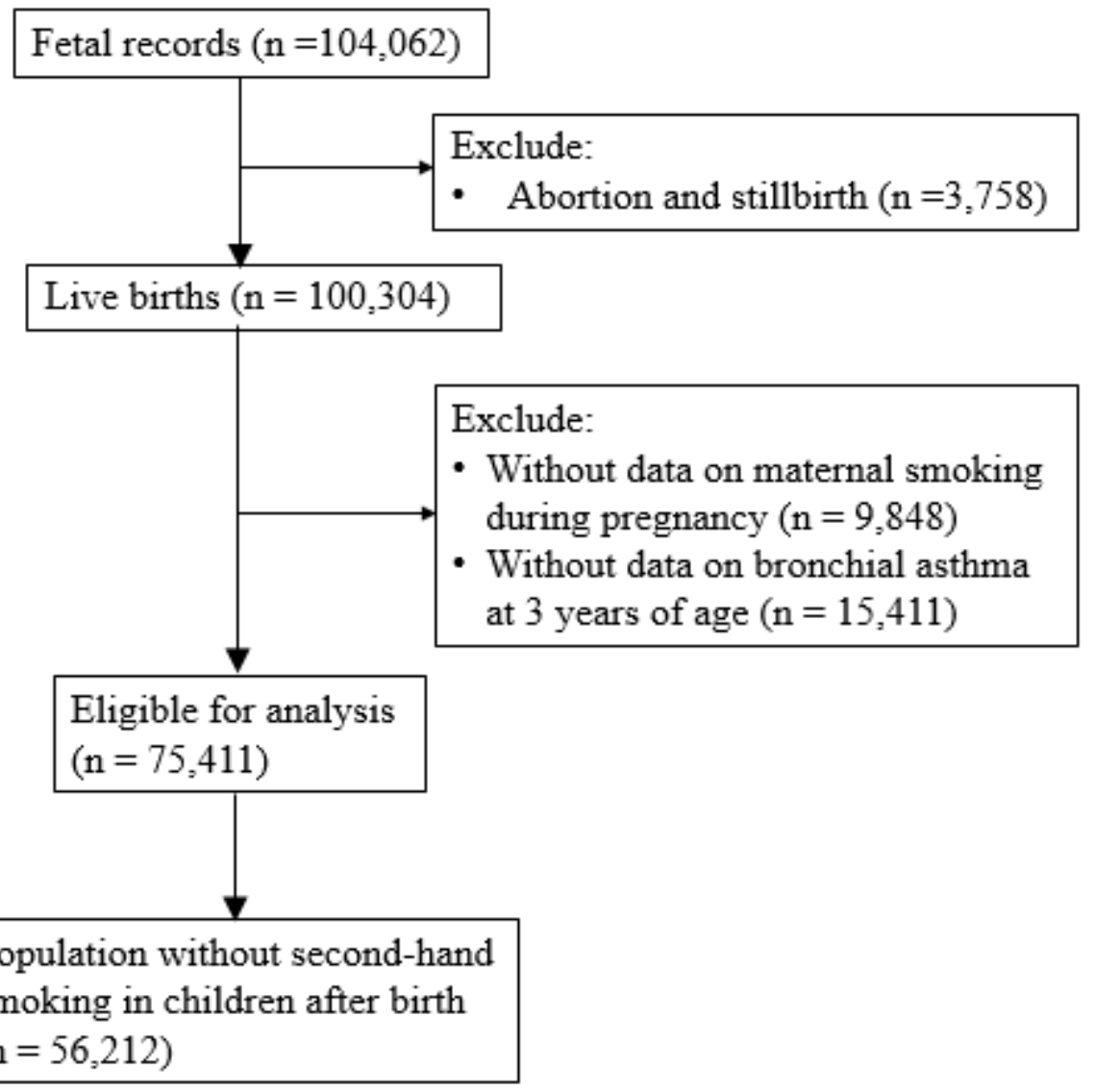

\section{Figure 1}

Flow chart of the study participants.

\section{Supplementary Files}

This is a list of supplementary files associated with this preprint. Click to download.

- RespRessupplement20211013.docx 